\title{
Empirical modelling of machining parameters for turning operations using multi- objective Taguchi method
}

\author{
A. Saha ${ }^{1 *}$ \\ ${ }^{1}$ Faculty of Production Engineering, Haldia Institute of Technology, \\ 721657 Haldia, West Bengal, India \\ *Email: alfa.nita2010@gmail.com
}

Phone: +919883738503; Fax: (+913224)252800

\begin{abstract}
This paper presents an effective approach for the optimisation of process parameters in the turning operation for machining ASTM A36 Mild Steel bar with multi-performance characteristics using multi-objective Taguchi method. Based on Taguchi orthogonal array, 27 experimental runs were performed to identify the optimal level of process parameters. The multiple performance characteristics including power consumption, surface roughness and frequency of tool vibration were the quality variables considered for the optimisation. An input-output inprocess parameter relationship model was developed using regression analysis for the power consumption, surface roughness and frequency of tool vibration. The optimum combination of machining parameters and their levels for the optimum multi-performance characteristics of the turning process was $\mathrm{A}_{1} \mathrm{~B}_{1} \mathrm{C}_{1}$ (i.e. speed: 160 r.p.m, feed rate: $0.08 \mathrm{~mm} / \mathrm{rev}$ and depth-of-cut: $0.1 \mathrm{~mm}$ ). This study will be very useful to shop floor engineers in deciding the levels of the turning parameters for optimal performance characteristics.
\end{abstract}

Keywords: ANOVA; Taguchi method; optimisation; regression analysis; Turning.

\section{INTRODUCTION}

Turning is one of the most basic machining processes in industrial production systems. It is carried out on a lathe that provides the power to turn the workpiece at a given rotational speed and feed the cutting tool at a specified rate and depth of cut. Researchers have attempted several approaches to identify multiple process parameter settings that can increase quality at higher productivity levels, requiring the turning process to be executed more efficiently [1-4]. Thus, it is of utmost important to identify the optimal parameter settings to increase tool life, improve surface accuracy, and reduce cutting force and chip thickness in turning operations. Cutting speed, feed rate, depth of cut, tool-workpiece material, tool geometry, and coolant conditions are the turning parameters that highly affect the performance [5-8]. Turning produces three cutting force components: the main cutting force i.e. thrust force, $\left(\mathrm{F}_{\mathrm{Z}}\right)$, which is produced in the cutting speed direction; feed force, $\left(F_{X}\right)$, which is produced in the feed rate direction; and radial force, $\left(F_{Y}\right)$, which is produced in radial direction and normal to the cutting speed). Out of the three force components, the cutting force (main force) constitutes about $70 \%$ to $80 \%$ of the total force ' $\mathrm{F}$ ' and is used to calculate the power ' $\mathrm{P}$ ' required to perform the machining operation. Power is the product of main cutting force and the cutting velocity and is a better criterion for design and selection of any machine tools. Power consumption may be used for 
monitoring the tool conditions [9-12]. Many researchers and practitioners have studied the effects of optimal selection of machining parameters in turning.

Anthony [13] has demonstrated the Taguchi quality loss function based on multiobjective optimisation technique for manufacturing processes with an example of the electronic assembly process and found considerable improvement in multiple quality characteristics in comparison to single quality characteristics. Multi-objective Taguchi method (MTM) approach has been used for the optimisation of the laser beam cutting process by Dubey and Yadava [14]. The authors found that quality characteristics were improved considerably. Sometimes, scientific methods based on Taguchi orthogonal array were used [15]. This method can analyse and provide optimum parameters for a given set of independent parameters and a response variable. Fong and Chen [16] presented an approach to optimise the process parameters in the turning of tool steels. They performed Taguchi experiments with eight independent parameters that included cutting speed, feed, and depth of cut, coating type, type of insert, chip breaker geometry, coolant, and band nose radius. The optimum turning parameters were determined based on grey relational grade that maximised the accuracy and minimised the surface roughness and dimensional precision. Several researchers and practitioners have applied grey relational analysis (GRA) to different machining processes that included electric discharge machining [17], determining tool condition in turning [18], chemical mechanical polishing [19], side milling [19, 20], and flank milling [21] to compare the performance of diamond tool carbide inserts in dry turning [22], and optimisation of drilling parameters to minimise surface roughness and burr height [23]. Lin [24] used grey relational analysis to optimise turning operations with multiple performance characteristics and analysed the tool life, cutting force, and surface roughness in turning operations. Al-Refaie et al. [25] applied the Taguchi method grey analysis (TMGA) to determine the optimal combination of control parameters in milling and measuring the machining performance such as the material removal rate and surface roughness. Based on the ANOVA, it was found that the feed rate was significant to the control parameters for responses. The machining parameters are usually selected based on either the experience or the proposed guidelines of the manufacturers. This selection procedure does not lead to the optimal and economically effective use of the machines and the quality of the surface generated. Hence, there is a necessity for a simple and effective experimental method for a multi-objective optimisation problem [11, 26-30].

The purpose of this paper is to present the application of multi-objective Taguchi method in selecting optimum turning conditions on multi-performance characteristics, namely the power consumption, surface roughness and frequency of tool vibration. In addition, significant controllable process parameters which affect the multi-performance characteristics in the turning process were determined. Further mathematical models were developed from the experimental results which were used in the quantification of power consumption, surface roughness and frequency of tool vibration. Thus, the results can be used by engineers willing to identify an optimal solution of the turning operation of ASTM A36 Mild Steel bar.

\section{METHODS AND MATERIALS}

\section{Experimental Setup}

The experiments were carried out on an experimental lathe setup. The workpiece material was ASTM A36 Mild Steel bar of $24 \mathrm{~mm}$ in diameter. The cutting tool was HSS MIRANDA S-400 (AISI T - 42). The composition percentage of the workpiece material 
is listed in Table 1. In the present experimental study, spindle speed, feed and depth of cut were considered as machining parameters. The machining parameters with their units and their levels as considered for experimentation are listed in Table 2. Flowchart of the methodology used is shown in Figure 1.

Table 1. Chemical composition of Mild Steel (ASTM A36) [31].

\begin{tabular}{cccccc}
\hline Material Composition & $\mathrm{C}$ & $\mathrm{Mn}$ & $\mathrm{Si}$ & $\mathrm{S}$ & $\mathrm{P}$ \\
\hline Weight Percentage (\%) & 0.15 & 0.79 & 0.22 & 0.022 & 0.030 \\
\hline
\end{tabular}

Table 2. Machining parameters and their limits.

\begin{tabular}{cclccc}
\hline Symbol & Machining Parameter & Unit & Level 1 & Level 2 & Level 3 \\
\hline A & Spindle Speed & RPM & 160 & 240 & 400 \\
B & Feed & $\mathrm{mm} / \mathrm{rev}$ & 0.08 & 0.16 & 0.32 \\
C & Depth of cut & $\mathrm{mm}$ & 0.1 & 0.15 & 0.2 \\
\hline
\end{tabular}

Table 3 shows the specifications of the Panther Lathe machine. This machine has been manufactured with a view to obtain the highest degree of working accuracy and it has been thoroughly tested for its performance to confirm IS 11118-1984, IS 1878(part I)-1971.

Table 3. Specifications of Panther Lathe [Model-2050/4].

\begin{tabular}{lll}
\hline Parameters & \multicolumn{1}{c}{ Value } & \multicolumn{1}{c}{ Unit } \\
\hline Length of bed & 3030 & $\mathrm{~mm}$ \\
Height of centre & 270 & $\mathrm{~mm}$ \\
Width of bed & 325 & $\mathrm{~mm}$ \\
Swing over cross slide & 325 & $\mathrm{~mm}$ \\
Swing in gap & 830 & $\mathrm{~mm}$ \\
Motor capacity & 3 & $\mathrm{HP}$ \\
No. of spindle speed / range & 8 & - \\
Spindle speed range & $30-1235$ & $\mathrm{rpm}$ \\
Spindle bore & 52 & $\mathrm{~mm}$ \\
Spindle nose & $\mathrm{A} 2$ Size 6 & - \\
Taper in centre sleeve & 4 & $\mathrm{MT}$ \\
Tail stock spindle diameter & 63 & $\mathrm{~mm}$ \\
Feed range & 40 & $\mathrm{~mm} / \mathrm{Rev}$. \\
Range of longitudinal speed per rev. & 0.064 to 1.98 & $\mathrm{~mm} / \mathrm{Rev}$. \\
Transverse feeds per revolution & 0.016 to 0.48 & $\mathrm{~mm} / \mathrm{Rev}$. \\
Threads no. range & $40 / 2$ to 60 & $\mathrm{TPI}$ \\
\hline
\end{tabular}

\section{Measurement of Quality Responses}

After cutting all the specimens, the roughness of the cut surface was measured by utilising the Mar Surf PS1 surface roughness tester. Arithmetic mean roughness $\left(R_{a}\right)$ was utilised as the surface finish parameter to demonstrate the surface quality of the machined specimens. Cutting forces were measured using the Lathe tool dynamometer and cutting tool vibration was measured using the PicoScope 2202. 


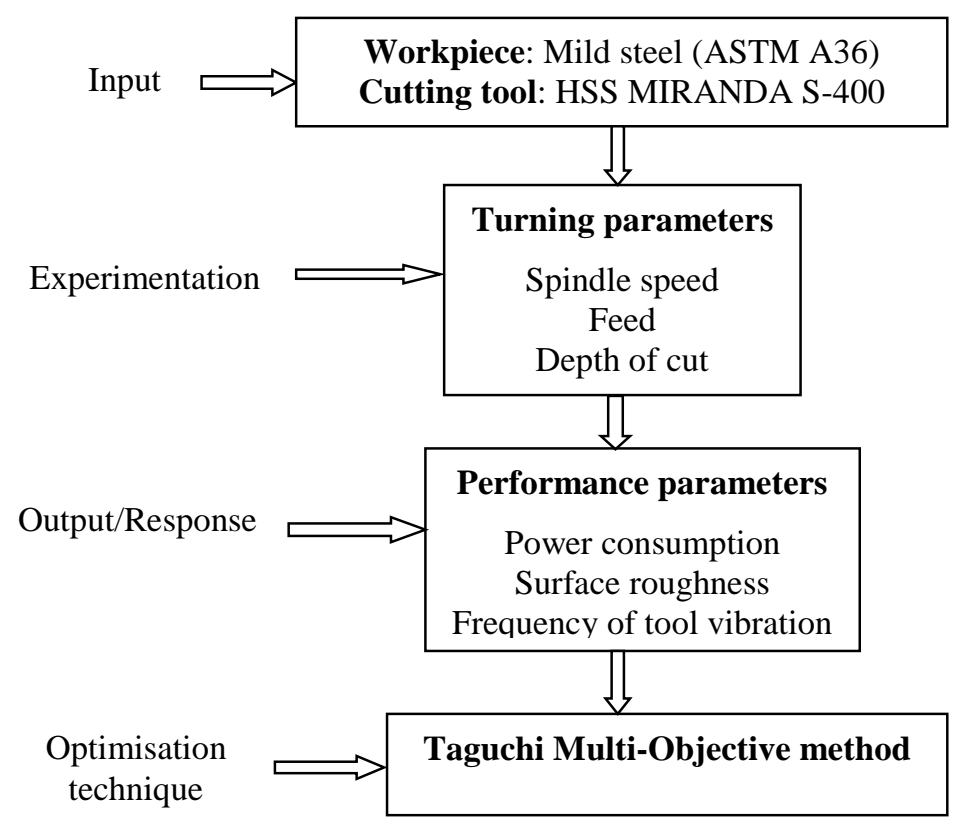

Figure 1. Flowchart of the methodology used.

The power to perform machining can be computed from $\mathrm{P}=\mathrm{F}_{\mathrm{c}} \times \mathrm{V}$, where, $\mathrm{P}=$ cutting power, $\mathrm{F}_{\mathrm{c}}=$ cutting or tangential force [this force is in the direction of primary motion. It constitutes about $70 \sim 80 \%$ of the total force] and $\mathrm{V}=$ cutting speed. Dynamometer is a cutting force measuring instrument used to measure the cutting forces coming on the tool tip on the Lathe Machine. The sensor is designed in such a way that it can be rigidly mounted on the tool post and the cutting tool can be fixed to the sensor directly. This feature will help to measure the forces accurately without loss of the force. The sensor is made of a single element with three different wheat stones strain gauge bridge. Provision was made to fix $1 / 2$ " size tool bit at the front side of the sensor.

Capacity

Excitation

Linearity

Accuracy

Cross-Sensitivity

Max. Over Load

\section{:X,Y,Z-Force500kg}

$10 \mathrm{Vdc}$

$: 2 \%$

$2 \%$

$5 \%$

$: 150$

\section{Taguchi and Multi-objective Taguchi Method}

Taguchi's robust design is a simple, systematic and more efficient technique for optimising the process parameters [32]. In this method, the main parameters which are assumed to have influence on the process results are located at different rows in a designed orthogonal array (OA). With such arrangement, completely randomised experiments can be conducted. An advantage of the Taguchi method is that it emphasises a mean performance characteristic value close to the target value rather than a value within certain specification limits, thus improving the product quality. Experimental conditions, cutting force and calculated power is presented in Table 4.In this present work, optimisation of welding operations using Taguchi's robust design methodology with multiple performance characteristics is proposed. In order to optimise the multiple performance characteristics, the Taguchi parametric design approach was not applied directly, since each performance characteristic may not have the same measurement unit 
and of the same category in the $\mathrm{S} / \mathrm{N}$ ratio analysis. Therefore, to solve problems of this kind, steps 1-3 were followed first, and then the traditional Taguchi technique for single response optimisation was performed.

Table 4. Experimental conditions, cutting force and calculated power.

\begin{tabular}{|c|c|c|c|c|c|c|}
\hline $\begin{array}{l}\text { Exp. } \\
\text { No }\end{array}$ & $\begin{array}{c}\text { Spindle } \\
\text { Speed } \\
\text { (RPM) }\end{array}$ & $\begin{array}{l}\text { Feed rate } \\
(\mathrm{mm} / \mathrm{rev})\end{array}$ & $\begin{array}{l}\text { Depth } \\
\text { of cut } \\
(\mathrm{mm})\end{array}$ & $\begin{array}{l}\text { Force, } \\
\mathrm{F}_{\mathrm{c}}(\mathrm{N})\end{array}$ & $\begin{array}{c}\text { Cutting speed, } \\
\mathrm{V}\left(\mathrm{m} \mathrm{min}^{-1}\right)\end{array}$ & $\begin{array}{l}\text { Power, } \\
\text { P (W) }\end{array}$ \\
\hline 1 & 160 & 0.08 & 0.15 & 48 & 12.06 & 9.65 \\
\hline 2 & 160 & 0.08 & 0.2 & 64 & 12.06 & 12.86 \\
\hline 3 & 160 & 0.32 & 0.15 & 192 & 12.06 & 38.6 \\
\hline 4 & 160 & 0.32 & 0.1 & 87.04 & 12.06 & 17.5 \\
\hline 5 & 160 & 0.16 & 0.1 & 43.68 & 12.06 & 8.8 \\
\hline 6 & 400 & 0.32 & 0.15 & 130.56 & 30.16 & 65.63 \\
\hline 7 & 240 & 0.16 & 0.1 & 50.68 & 18.09 & 15.28 \\
\hline 8 & 400 & 0.16 & 0.15 & 70.52 & 30.16 & 35.5 \\
\hline 9 & 160 & 0.16 & 0.2 & 107.36 & 12.06 & 21.6 \\
\hline 10 & 400 & 0.16 & 0.1 & 54.68 & 30.16 & 27.5 \\
\hline 11 & 240 & 0.16 & 0.15 & 80.52 & 18.09 & 24.28 \\
\hline 12 & 400 & 0.08 & 0.2 & 64 & 30.16 & 32.17 \\
\hline 13 & 240 & 0.32 & 0.1 & 100.04 & 18.09 & 30.16 \\
\hline 14 & 240 & 0.08 & 0.1 & 25 & 18.09 & 7.54 \\
\hline 15 & 240 & 0.08 & 0.15 & 48 & 18.09 & 14.47 \\
\hline 16 & 160 & 0.08 & 0.1 & 33 & 12.06 & 6.63 \\
\hline 17 & 240 & 0.08 & 0.2 & 64 & 18.09 & 19.3 \\
\hline 18 & 160 & 0.32 & 0.2 & 174.08 & 12.06 & 35 \\
\hline 19 & 400 & 0.08 & 0.15 & 38 & 30.16 & 19.1 \\
\hline 20 & 160 & 0.16 & 0.15 & 80.52 & 12.06 & 16.2 \\
\hline 21 & 400 & 0.16 & 0.2 & 127.36 & 30.16 & 64.02 \\
\hline 22 & 240 & 0.32 & 0.15 & 192 & 18.09 & 57.9 \\
\hline 23 & 400 & 0.32 & 0.1 & 109.36 & 30.16 & 56 \\
\hline 24 & 240 & 0.32 & 0.2 & 194.08 & 18.09 & 58.5 \\
\hline 25 & 400 & 0.32 & 0.2 & 174.08 & 30.16 & 87.5 \\
\hline 26 & 240 & 0.16 & 0.2 & 127.36 & 18.09 & 38.4 \\
\hline 27 & 400 & 0.08 & 0.1 & 27.34 & 30.16 & 13.74 \\
\hline
\end{tabular}

Step 1: The loss function was normalised corresponding to each performance characteristic as follows-

$$
y_{i j}=\frac{L_{i j}}{L_{i}^{*}}
$$

where, $y_{i j}$ is the normalised quality loss associated with the ith quality characteristic at the $\mathrm{jth}$ trial condition, and it varies from a minimum of zero to a maximum of 1 . $\mathrm{L}_{\mathrm{ij}}$ is the quality loss or MSD for the ith quality characteristic at the jth trial, and $\mathrm{Li}_{\mathrm{i}}$ * is the maximum quality loss for the ith quality characteristic among all the experimental runs.

Step 2: A weighting method was applied to determine the importance of each normalised loss function. The total normalised quality loss function $\mathrm{Y}_{\mathrm{j}}$ in the jth experiment is given under: 


$$
Y_{j}=\sum_{i=1}^{k} W_{i} y_{i j}
$$

where, $\mathrm{W}_{\mathrm{i}}$ represents the weighting factor for the ith quality characteristic and $\mathrm{k}$ is the total number of quality characteristics.

Step 3: In multi-objective optimisation, a single overall $\mathrm{S} / \mathrm{N}$ ratio for all quality characteristics is computed in place of separate $\mathrm{S} / \mathrm{N}$ ratios for each of the quality characteristic. This overall $\mathrm{S} / \mathrm{N}$ ratio is known as multiple $\mathrm{S} / \mathrm{N}$ ratio (MSNR). The total loss function was transformed into a multiple $\mathrm{S} / \mathrm{N}$ ratio (MSNR) as follows:

$$
M S N R=-10 \log _{10}\left(Y_{j}\right)
$$

Based on the multiple S/N ratio (MSNR), the optimal factors or level combination were determined like the traditional Taguchi technique. Finally, the optimal process parameters were verified through the confirmation experiment. Usually, there are three categories of quality characteristics in the analysis of $\mathrm{S} / \mathrm{N}$ ratio: nominal the better, the lower the better and the higher the better. The summary statistics $\eta(\mathrm{dB})$ of the HB performance characteristics is expressed as follows:

$$
\eta=-10 \log _{10}\left[\frac{1}{\mathrm{n}} \sum_{\mathrm{i}=1}^{\mathrm{n}} \frac{1}{\mathrm{y}_{\mathrm{i}}^{2}}\right]
$$

where $\mathrm{i}=1,2 \ldots . \mathrm{n}$

The summary statistics $\eta(\mathrm{dB})$ of the LB performance characteristics is expressed as follows:

$$
\eta=-10 \log _{10}\left[\frac{1}{\mathrm{n}} \sum_{\mathrm{i}=1}^{\mathrm{n}} \mathrm{y}_{\mathrm{i}}^{2}\right]
$$

where $\mathrm{i}=1,2 \ldots \mathrm{n}$

\section{RESULTS AND DISCUSSION}

\section{Multi-objective optimisation}

From Table 5, quality loss values for different quality characteristics (smaller-is-better for power consumption, frequency of tool vibration and also for surface roughness) in each experimental run were calculated using Eqs. (4). These quality loss values are shown in Table 6. The normalised quality loss values for all the quality characteristics in each experimental run have been calculated using Eq. (1) as shown in Table 7. The total normalised quality loss values (TNQL) and MSNR for multiple quality characteristics for power consumption, frequency of tool vibration and also for surface roughness have been calculated using Eqs. (2) and (3), respectively [11]. These results are shown in Table 8. In calculating the total normalised quality loss values, three unequal weights, $\mathrm{w}_{1}=0.4$ for power consumption, $\mathrm{w}_{2}=0.4$ for surface roughness, and $\mathrm{w}_{3}=0.2$ for frequency of tool vibration were used. Higher weighting factor was assigned to the power consumption and also for surface roughness because it is more important compared to the frequency of tool vibration in order to achieve good quality in the turning process. The effect of different control factors on MSNR is shown in Table 9. The optimum set of parameters was A in the first level, B in the first level, and $\mathrm{C}$ in the first level respectively (A1B1C1). 
Table 5. Experimental design and collected response data.

\begin{tabular}{ccccccc}
\hline & \multicolumn{3}{c}{ Input Parameters } & \multicolumn{2}{c}{ Responses } \\
\cline { 2 - 7 } Exp. & $\begin{array}{c}\text { Spindle } \\
\text { No. }\end{array}$ & $\begin{array}{c}\text { Feed } \\
(\mathrm{mm} / \mathrm{rev})\end{array}$ & $\begin{array}{c}\text { Depth } \\
\text { of cut } \\
(\mathrm{RPM})\end{array}$ & $\begin{array}{c}\text { Power } \\
\text { consumption } \\
\mathrm{P}(\mathrm{W})\end{array}$ & $\begin{array}{c}\text { Surface } \\
\text { roughness } \\
\mathrm{R}_{\mathrm{a}}(\mu \mathrm{m})\end{array}$ & $\begin{array}{c}\text { Frequency of } \\
\text { tool vibration } \\
\mathrm{f}(\mathrm{Hz})\end{array}$ \\
\hline 1 & 160 & 0.08 & 0.15 & 9.65 & 1.97 & 270.7 \\
2 & 160 & 0.08 & 0.2 & 12.86 & 2.01 & 281 \\
3 & 160 & 0.32 & 0.15 & 38.6 & 6.84 & 335 \\
4 & 160 & 0.32 & 0.1 & 17.5 & 6.16 & 322.9 \\
5 & 160 & 0.16 & 0.1 & 8.8 & 2.58 & 295 \\
6 & 400 & 0.32 & 0.15 & 65.63 & 5.46 & 395 \\
7 & 240 & 0.16 & 0.1 & 15.28 & 2.38 & 326.5 \\
8 & 400 & 0.16 & 0.15 & 35.5 & 1.68 & 362 \\
9 & 160 & 0.16 & 0.2 & 21.6 & 3.02 & 310 \\
10 & 400 & 0.16 & 0.1 & 27.5 & 2.29 & 347 \\
11 & 240 & 0.16 & 0.15 & 24.28 & 2.20 & 337.7 \\
12 & 400 & 0.08 & 0.2 & 32.17 & 1.66 & 355 \\
13 & 240 & 0.32 & 0.1 & 30.16 & 6.01 & 350 \\
14 & 240 & 0.08 & 0.1 & 7.54 & 1.59 & 297 \\
15 & 240 & 0.08 & 0.15 & 14.47 & 1.80 & 321 \\
16 & 160 & 0.08 & 0.1 & 6.63 & 1.88 & 260 \\
17 & 240 & 0.08 & 0.2 & 19.3 & 1.82 & 327 \\
18 & 160 & 0.32 & 0.2 & 35 & 6.72 & 347 \\
19 & 400 & 0.08 & 0.15 & 19.1 & 1.54 & 340 \\
20 & 160 & 0.16 & 0.15 & 16.2 & 3.42 & 302.7 \\
21 & 400 & 0.16 & 0.2 & 64.02 & 2.60 & 384 \\
22 & 240 & 0.32 & 0.15 & 57.9 & 5.84 & 370 \\
23 & 400 & 0.32 & 0.1 & 56 & 5.82 & 376 \\
24 & 240 & 0.32 & 0.2 & 58.5 & 6.28 & 375.7 \\
25 & 400 & 0.32 & 0.2 & 87.5 & 5.89 & 420 \\
26 & 240 & 0.16 & 0.2 & 38.4 & 2.84 & 357 \\
27 & 400 & 0.08 & 0.1 & 13.74 & 1.38 & 322 \\
\hline & & & & & & \\
\end{tabular}

\section{Confirmation test}

After obtaining the optimal level of the machining parameters, the next step was to verify the improvement of the performance characteristics using this optimal combination. The confirmation experiment was performed by conducting a test with a specific combination of the factors and levels previously evaluated. Then, the predicted value of MSNR $(\hat{\gamma})$ at the optimum parameter levels was evaluated by using the following equation:

$$
\hat{\gamma}=\gamma_{m}+\sum_{i=0}^{o}\left(\overline{\gamma_{J}}-\gamma_{m}\right)
$$

where $\gamma_{m}$ is the mean MSNR of all experimental runs, $\bar{\gamma}_{j}$ is the average MSNR at the optimum level and o is the number of machining parameters that significantly affects the multiple performance characteristics.

Finally, experiments were conducted by using the best process parameters for optimum performance characteristics, and the mean results are presented in Table 10. Hence, using the present approach, turning of ASTM A36 Mild Steel was successfully optimised for power consumption, frequency of tool vibration and also for surface roughness. 
Table 6. Quality loss values for weld bead width and weld bead hardness.

\begin{tabular}{cccccccc}
\hline $\begin{array}{c}\text { Expt. } \\
\text { No }\end{array}$ & $\begin{array}{c}\text { Power } \\
\text { consumption }\end{array}$ & $\begin{array}{c}\text { Surface } \\
\text { roughness }\end{array}$ & $\begin{array}{c}\text { Frequency } \\
\text { of tool } \\
\text { vibration }\end{array}$ & $\begin{array}{c}\text { Expt. } \\
\text { No }\end{array}$ & $\begin{array}{c}\text { Power } \\
\text { consumption }\end{array}$ & $\begin{array}{c}\text { Surface } \\
\text { roughness }\end{array}$ & $\begin{array}{c}\text { Frequency of } \\
\text { tool } \\
\text { vibration }\end{array}$ \\
\hline 1 & -19.691 & -5.889 & -48.650 & 15 & -23.209 & -5.105 & -50.130 \\
2 & -22.185 & -6.064 & -48.974 & 16 & -16.430 & -5.483 & -48.300 \\
3 & -31.732 & -16.701 & -50.501 & 17 & -25.711 & -5.201 & -50.291 \\
4 & -24.861 & -15.792 & -50.181 & 18 & -30.881 & -16.547 & -50.807 \\
5 & -18.890 & -8.232 & -49.396 & 19 & -25.621 & -3.750 & -50.630 \\
6 & -36.342 & -14.744 & -51.932 & 20 & -24.190 & -10.681 & -49.620 \\
7 & -23.682 & -7.532 & -50.278 & 21 & -36.126 & -8.299 & -51.687 \\
8 & -31.005 & -4.506 & -51.174 & 22 & -35.254 & -15.328 & -51.364 \\
9 & -26.689 & -9.600 & -49.827 & 23 & -34.964 & -15.299 & -51.504 \\
10 & -28.787 & -7.197 & -50.807 & 24 & -35.343 & -15.959 & -51.497 \\
11 & -27.705 & -6.848 & -50.571 & 25 & -38.840 & -15.402 & -52.465 \\
12 & -30.149 & -4.402 & -51.005 & 26 & -31.687 & -9.066 & -51.053 \\
13 & -29.589 & -15.578 & -50.881 & 27 & -22.760 & -2.798 & -50.157 \\
14 & -17.547 & -4.028 & -49.455 & & & & \\
\hline
\end{tabular}

Table 7. Normalised quality loss values.

\begin{tabular}{cccccccc}
\hline $\begin{array}{c}\text { Expt. } \\
\text { No }\end{array}$ & $\begin{array}{c}\text { Power } \\
\text { consumption }\end{array}$ & $\begin{array}{c}\text { Surface } \\
\text { roughness }\end{array}$ & $\begin{array}{c}\text { Frequency of } \\
\text { tool vibration }\end{array}$ & $\begin{array}{c}\text { Expt. } \\
\text { No }\end{array}$ & $\begin{array}{c}\text { Power } \\
\text { consumption }\end{array}$ & $\begin{array}{c}\text { Surface } \\
\text { roughness }\end{array}$ & $\begin{array}{c}\text { Frequency of } \\
\text { tool vibration }\end{array}$ \\
\hline 1 & 0.507 & 0.353 & 0.937 & 15 & 0.598 & 0.306 & 0.965 \\
2 & 0.571 & 0.363 & 0.943 & 16 & 0.423 & 0.328 & 0.930 \\
3 & 0.817 & 1.000 & 0.972 & 17 & 0.662 & 0.311 & 0.968 \\
4 & 0.640 & 0.946 & 0.966 & 18 & 0.795 & 0.991 & 0.978 \\
5 & 0.486 & 0.493 & 0.951 & 19 & 0.660 & 0.225 & 0.975 \\
6 & 0.936 & 0.883 & 1.000 & 20 & 0.623 & 0.640 & 0.955 \\
7 & 0.610 & 0.451 & 0.968 & 21 & 0.930 & 0.497 & 0.995 \\
8 & 0.798 & 0.270 & 0.985 & 22 & 0.908 & 0.918 & 0.989 \\
9 & 0.687 & 0.575 & 0.959 & 23 & 0.900 & 0.916 & 0.992 \\
10 & 0.741 & 0.431 & 0.978 & 24 & 0.910 & 0.956 & 0.992 \\
11 & 0.713 & 0.410 & 0.974 & 25 & 1.000 & 0.922 & 1.010 \\
12 & 0.776 & 0.264 & 0.982 & 26 & 0.816 & 0.543 & 0.983 \\
13 & 0.762 & 0.933 & 0.980 & 27 & 0.586 & 0.168 & 0.966 \\
14 & 0.452 & 0.241 & 0.952 & & & & \\
\hline
\end{tabular}

Table 8. Total normalised quality loss values (TNQL) and Multiple S/N ratios (MSNR).

\begin{tabular}{cccccc}
\hline Expt. No & TNQL & MSNR (dB) & Expt. No & TNQL & MSNR (dB) \\
\hline 1 & 0.531 & 2.747 & 15 & 0.554 & 2.562 \\
2 & 0.562 & 2.500 & 16 & 0.487 & 3.129 \\
3 & 0.921 & 0.356 & 17 & 0.583 & 2.343 \\
4 & 0.828 & 0.822 & 18 & 0.910 & 0.409 \\
5 & 0.582 & 2.351 & 19 & 0.549 & 2.607 \\
6 & 0.927 & 0.327 & 20 & 0.696 & 1.574 \\
7 & 0.618 & 2.091 & 21 & 0.770 & 1.136 \\
8 & 0.624 & 2.046 & 22 & 0.928 & 0.325 \\
9 & 0.697 & 1.570 & 23 & 0.925 & 0.339 \\
10 & 0.664 & 1.775 & 24 & 0.945 & 0.248 \\
11 & 0.644 & 1.910 & 25 & 0.971 & 0.128 \\
12 & 0.612 & 2.130 & 26 & 0.740 & 1.307 \\
13 & 0.874 & 0.586 & 27 & 0.495 & 3.058 \\
14 & 0.468 & 3.301 & & & \\
\hline
\end{tabular}


Table 9. Multiple $\mathrm{S} / \mathrm{N}$ responses (average factor effect at different levels).

\begin{tabular}{cccccc}
\hline & & \multicolumn{4}{c}{ Mean of multiple S/N ratio (dB) } \\
\cline { 3 - 6 } Symbol & Factors & Level I & Level II & Level II & Max- Min \\
\hline A & Spindle Speed & $1.718^{*}$ & 1.630 & 1.505 & 0.213 \\
B & Feed & $2.708^{*}$ & 1.751 & 0.393 & 2.315 \\
C & Depth of cut & $1.939^{*}$ & 1.606 & 1.308 & 0.631 \\
\hline
\end{tabular}

[* Shows optimal turning parameters]

Table 10. Results of the confirmation experiment.

\begin{tabular}{|c|c|c|c|}
\hline \multirow[b]{3}{*}{ Setting Level } & \multirow{2}{*}{$\begin{array}{l}\text { Initial machining } \\
\text { parameters }\end{array}$} & \multicolumn{2}{|c|}{ Optimal machining parameters } \\
\hline & & Prediction & Experiment \\
\hline & $\mathrm{A}_{1} \mathrm{~B}_{1} \mathrm{C}_{2}$ & $\mathrm{~A}_{1} \mathrm{~B}_{1} \mathrm{C}_{1}$ & $\mathrm{~A}_{1} \mathrm{~B}_{1} \mathrm{C}_{1}$ \\
\hline Power consumption $\mathrm{P}(\mathrm{W})$ & 9.65 & & 6.63 \\
\hline Surface roughness $R_{a}(\mu m)$ & 1.97 & & 1.88 \\
\hline Frequency of tool vibration $\mathrm{f}(\mathrm{Hz})$ & 270.7 & & 260 \\
\hline Multiple $\mathrm{S} / \mathrm{N}$ ratio $(\mathrm{dB})$ & 2.747439 & 3.12962 & 3.128776 \\
\hline
\end{tabular}

Improvement in multiple $\mathrm{S} / \mathrm{N}$ ratio $=0.381337 \mathrm{~dB}$

Table 11. Log transformed for process parameters.

\begin{tabular}{cccccccccccc}
\hline $\mathrm{N}$ & $\ln (\mathrm{N})$ & $\mathrm{f}$ & $\ln (\mathrm{f})$ & $\mathrm{d}_{\text {cut }}$ & $\ln \left(\mathrm{d}_{\text {cut }}\right)$ & $\mathrm{N}$ & $\ln (\mathrm{N})$ & $\mathrm{f}$ & $\ln (\mathrm{f})$ & $\mathrm{d}_{\text {cut }}$ & $\ln \left(\mathrm{d}_{\text {cut }}\right)$ \\
\hline 160 & 5.075 & 0.08 & -2.526 & 0.15 & -1.897 & 240 & 5.481 & 0.08 & -2.526 & 0.15 & -1.897 \\
160 & 5.075 & 0.08 & -2.526 & 0.2 & -1.609 & 160 & 5.075 & 0.08 & -2.526 & 0.1 & -2.303 \\
160 & 5.075 & 0.32 & -1.139 & 0.15 & -1.897 & 240 & 5.481 & 0.08 & -2.526 & 0.2 & -1.609 \\
160 & 5.075 & 0.32 & -1.139 & 0.1 & -2.303 & 160 & 5.075 & 0.32 & -1.139 & 0.2 & -1.609 \\
160 & 5.075 & 0.16 & -1.833 & 0.1 & -2.303 & 400 & 5.991 & 0.08 & -2.526 & 0.15 & -1.897 \\
400 & 5.991 & 0.32 & -1.139 & 0.15 & -1.897 & 160 & 5.075 & 0.16 & -1.833 & 0.15 & -1.897 \\
240 & 5.481 & 0.16 & -1.833 & 0.1 & -2.303 & 400 & 5.991 & 0.16 & -1.833 & 0.2 & -1.609 \\
400 & 5.991 & 0.16 & -1.833 & 0.15 & -1.897 & 240 & 5.481 & 0.32 & -1.139 & 0.15 & -1.897 \\
160 & 5.075 & 0.16 & -1.833 & 0.2 & -1.609 & 400 & 5.991 & 0.32 & -1.139 & 0.1 & -2.303 \\
400 & 5.991 & 0.16 & -1.833 & 0.1 & -2.303 & 240 & 5.481 & 0.32 & -1.139 & 0.2 & -1.609 \\
240 & 5.481 & 0.16 & -1.833 & 0.15 & -1.897 & 400 & 5.991 & 0.32 & -1.139 & 0.2 & -1.609 \\
400 & 5.991 & 0.08 & -2.526 & 0.2 & -1.609 & 240 & 5.481 & 0.16 & -1.833 & 0.2 & -1.609 \\
240 & 5.481 & 0.32 & -1.139 & 0.1 & -2.303 & 400 & 5.991 & 0.08 & -2.526 & 0.1 & -2.303 \\
\hline
\end{tabular}

\section{Regression Analysis of Performance Characteristics}

Regression analysis [22] for power consumption $\left(\mathrm{P}_{c}\right)$, surface roughness $\left(\mathrm{R}_{\mathrm{a}}\right)$ and frequency of tool vibration (fv) of the materials was obtained by using the statistical software MINITAB 13. The correlations were formed for process parameters by assuming a log transformed response variable and are listed in Tables 11 and 12. The following model was assumed for the best curve fitting:

$$
\ln (\mathrm{Y})=\beta_{0}+\beta_{1} \ln (\mathrm{N})+\beta_{2} \ln (\mathrm{f})+\beta_{3} \ln (\mathrm{doc})
$$

where, $Y$ is the performance characteristics and $\beta_{0}, \beta_{1}, \beta_{2}, \beta_{3}$ are regression coefficients. 
Table 12. Log transformed for performance characteristics.

\begin{tabular}{cccccccccccc}
\hline $\mathrm{P}_{\mathrm{c}}$ & $\ln \left(\mathrm{P}_{\mathrm{c}}\right)$ & $\mathrm{R}_{\mathrm{a}}$ & $\ln \left(\mathrm{R}_{\mathrm{a}}\right)$ & $\mathrm{f.v}$ & $\ln (\mathrm{f} . \mathrm{v})$ & $\mathrm{P}_{\mathrm{c}}$ & $\ln \left(\mathrm{P}_{\mathrm{c}}\right)$ & $\mathrm{R}_{\mathrm{a}}$ & $\ln \left(\mathrm{R}_{\mathrm{a}}\right)$ & f.v & $\ln$ (f.v) \\
\hline 9.65 & 2.267 & 1.97 & 0.678 & 270.7 & 5.601 & 14.47 & 2.672 & 1.8 & 0.588 & 321 & 5.771 \\
12.86 & 2.554 & 2.01 & 0.698 & 281 & 5.638 & 6.63 & 1.892 & 1.88 & 0.631 & 260 & 5.561 \\
38.6 & 3.653 & 6.84 & 1.923 & 335 & 5.814 & 19.3 & 2.960 & 1.82 & 0.599 & 327 & 5.790 \\
17.5 & 2.862 & 6.16 & 1.818 & 322.9 & 5.777 & 35 & 3.555 & 6.72 & 1.905 & 347 & 5.849 \\
8.8 & 2.175 & 2.58 & 0.948 & 295 & 5.687 & 19.1 & 2.950 & 1.54 & 0.432 & 340 & 5.829 \\
65.63 & 4.184 & 5.46 & 1.697 & 395 & 5.979 & 16.2 & 2.785 & 3.42 & 1.230 & 302.7 & 5.713 \\
15.28 & 2.727 & 2.38 & 0.867 & 326.5 & 5.788 & 64.02 & 4.159 & 2.6 & 0.956 & 384 & 5.951 \\
35.5 & 3.570 & 1.68 & 0.519 & 362 & 5.892 & 57.9 & 4.059 & 5.84 & 1.765 & 370 & 5.914 \\
21.6 & 3.073 & 3.02 & 1.105 & 310 & 5.737 & 56 & 4.025 & 5.82 & 1.761 & 376 & 5.930 \\
27.5 & 3.314 & 2.29 & 0.829 & 347 & 5.849 & 58.5 & 4.069 & 6.28 & 1.837 & 375.7 & 5.929 \\
24.28 & 3.190 & 2.2 & 0.788 & 337.7 & 5.822 & 87.5 & 4.472 & 5.89 & 1.773 & 420 & 6.040 \\
32.17 & 3.471 & 1.66 & 0.507 & 355 & 5.872 & 38.4 & 3.648 & 2.84 & 1.044 & 357 & 5.878 \\
30.16 & 3.407 & 6.01 & 1.793 & 350 & 5.858 & 13.74 & 2.620 & 1.38 & 0.322 & 322 & 5.775 \\
\hline
\end{tabular}

\section{Quantification of power consumption}

The regression analysis results for power consumption are presented in Table 13, which yielded the correlation between the power consumption and process parameters.

$$
\ln (\mathrm{Pc})=1.66+0.960 \ln (\mathrm{N})+0.872 \ln (\mathrm{f})+1.11 \ln (\mathrm{doc})
$$

The above equation can also be expressed in exponential form as follows:

$$
\mathrm{P}_{\mathrm{C}}=5.259(\mathrm{~N})^{0.960}(\mathrm{f})^{0.872}(\text { d.o.c })^{1.11}
$$

Table 13. Coefficients and intercepts for power consumption.

\begin{tabular}{ccccc}
\hline Predictor & Coef & SE Coef & $\mathrm{T}$ & $\mathrm{P}$ \\
\hline Constant & 1.6653 & 0.4210 & 3.93 & 0.001 \\
$\ln (\mathrm{N})$ & 0.96005 & 0.06779 & 14.16 & 0.000 \\
$\ln (\mathrm{f})$ & 0.87202 & 0.04491 & 19.42 & 0.000 \\
$\ln (\mathrm{doc})$ & 1.11350 & 0.08939 & 12.46 & 0.000 \\
\hline $\mathrm{S}=0.1321$ & $\mathrm{R}-\mathrm{Sq}=97.0 \%$ & $\mathrm{R}-\mathrm{Sq}(\operatorname{adj})=96.6 \%$
\end{tabular}

\section{Quantification of surface roughness}

Similarly, the regression analysis results for surface roughness are presented in Table 14 which yielded the correlation between the surface roughness and process parameters.

$$
\ln (\mathrm{Ra})=4.47-0.257 \ln (\mathrm{N})+0.910 \ln (\mathrm{f})+0.152 \ln (\mathrm{doc})
$$

The above equation can also be expressed in exponential form as follows:

$$
\mathrm{R}_{\mathrm{a}}=87.36(\mathrm{~N})^{-0.257}(\mathrm{f}){ }^{0.910}(\text { d.o.c })^{0.152}
$$

Table 14. Coefficients and intercepts for surface roughness.

\begin{tabular}{ccccc}
\hline Predictor & Coef & SE Coef & $\mathrm{T}$ & $\mathrm{P}$ \\
\hline Constant & 4.4726 & 0.5132 & 8.71 & 0.000 \\
$\ln (\mathrm{N})$ & -0.25731 & 0.08265 & -3.11 & 0.005 \\
$\ln (\mathrm{f})$ & 0.91010 & 0.05475 & 16.62 & 0.00 \\
$\ln (\mathrm{doc})$ & 0.1517 & $0 . .1090$ & 1.39 & 0.177 \\
\hline $\mathrm{S}=0.1610$ & $\mathrm{R}-\mathrm{Sq}=92.6 \%$ & $\mathrm{R}-\mathrm{Sq}(\mathrm{adj})=91.6 \%$
\end{tabular}




\section{Quantification of Frequency of Tool Vibration}

The regression analysis results for frequency of tool vibration are presented in Table 15 which yielded the correlation between the frequency of tool vibration and process parameters.

$$
\ln (\mathrm{f} . \mathrm{v})=5.13+0.208 \ln (\mathrm{N})+0.125 \ln (\mathrm{f})+0.122 \ln (\mathrm{doc})
$$

The above equation can also be expressed in the exponential form as follows:

$$
\text { f.v }=169.01(\mathrm{~N})^{0.208}(\mathrm{f})^{0.125}(\text { d.o.c })^{0.122}
$$

Table 15. Coefficients and intercepts for frequency of tool vibration.

\begin{tabular}{ccccc}
\hline Predictor & Coef & SE Coef & $\mathrm{T}$ & $\mathrm{P}$ \\
\hline Constant & 5.13002 & 0.07546 & 67.99 & 0.000 \\
$\ln (\mathrm{N})$ & 0.20810 & 0.01215 & 17.13 & 0.000 \\
$\ln (\mathrm{f})$ & 0.124950 & 0.008050 & 15.52 & 0.000 \\
$\ln (\mathrm{doc})$ & 0.12209 & 0.01602 & 7.62 & 0.000 \\
\hline $\mathrm{S}=0.02367$ & $\mathrm{R}-\mathrm{Sq}=96.3 \%$ & $\mathrm{R}-\mathrm{Sq}(\mathrm{adj})=$ & $=95.8 \%$
\end{tabular}

The regression analysis Eqs. (8), (10) and (12) determined the value of power consumption, surface roughness and frequency of tool vibration respectively for the turning of ASTM A36 Mild Steel. This would serve as a useful guide for selecting the proper values of process parameters to obtain the desired power consumption, surface roughness, and frequency of tool vibration of the turned product. It can be seen from Table 16 that p-values for the response power consumption, surface roughness and frequency of tool vibration were less than 0.05 , which showed that they were significant. Also, the values of R-sq (adj) were more than 90\%, which indicated a good fit. It confirmed that the model has adequately described the observed data.

Table 16. ANOVA for power consumption, surface roughness and frequency of tool vibration.

\begin{tabular}{lccccc}
\hline \multicolumn{1}{c}{ Source } & DF & SS & MS & F & P \\
\hline \multicolumn{7}{c}{ Power consumption } \\
\hline Regression & 3 & 12.7805 & 4.2602 & 244.25 & 0.000 \\
Residual Error & 23 & 0.4012 & 0.0174 & & \\
Total & 26 & 13.1816 \\
\hline \multicolumn{7}{c}{ Surface roughness } \\
\hline Regression & 3 & 7.4646 & 2.4882 & 95.98 & 0.000 \\
\hline Residual Error & 23 & 0.5962 & 0.0259 & & \\
\hline Total & 26 & 8.0609 \\
\hline \multicolumn{7}{c}{ Frequency of tool vibration } \\
\hline Regression & 3 & 0.33190 & 0.11063 & 197.43 & 0.000 \\
\hline Residual Error & 23 & 0.01289 & 0.00056 \\
\hline Total & 26 & 0.34479 \\
\hline
\end{tabular}

\section{CONCLUSIONS}

In this paper, an attempt has been made for the optimisation of the turning process of mild steel with multi-performance characteristics based on the combined full factorial design 
of experiments and Grey relational analysis. Based on the results of the present study, the following conclusions are drawn:

- $\quad$ The optimum combination of turning parameters and their levels for the optimum multi-performance characteristics of turning process was $\mathrm{A}_{1} \mathrm{~B}_{1} \mathrm{C}_{1}$ (i.e. speed160 r.p.m., feed rate $-0.08 \mathrm{~mm} / \mathrm{rev}$ and depth-of-cut $-0.1 \mathrm{~mm}$ ).

- Among the tested parameters, the feed rate showed the strongest correlation to power consumption and surface roughness.

- Confirmation test results proved that the determined optimum condition of turning parameters satisfied the real requirements.

Regression models correlating power consumption, surface roughness and frequency of tool vibration with process parameters have also been obtained. These equations provide a useful guide for setting proper values of turning parameters as to obtain the desired power consumption, surface roughness and frequency of tool vibration. Further into the future, researchers might attempt to consider the other performance criteria, such as tool wear, surface morphology of machined surface, MRR etc. as output parameters.

\section{ACKNOWLEDGEMENTS}

The author is very thankful to the reviewers for their constructive comments and suggestions on how to improve the quality of this paper. The author gratefully acknowledges the kind support and cooperation provided by NITTTR Kolkata.

\section{REFERENCES}

[1] Sahid NSM, Rahman MM, Kadirgama K, Ramasamy D, Maleque MA, Noor MM. Experimental investigation on the performance of the $\mathrm{TiO}_{2}$ and $\mathrm{ZnO}$ hybrid nanocoolant in ethylene glycol mixture towards AA6061-T6 machining. International Journal of Automotive and Mechanical Engineering. 2017;14:391326.

[2] Najiha MS, Rahman MM, Kadirgama K. Minimum quantity lubrication: Quantifying non-deterministic component of sustainability index for machining operations. International Journal of Automotive and Mechanical Engineering. 2016;13:3190-200.

[3] Najiha MS, Rahman MM, Kadirgama K. Machining performance of aluminum alloy 6061-t6 on surface finish using minimum quantity lubrication. International Journal of Automotive and Mechanical Engineering. 2015;11:2699-712.

[4] Najiha M, Rahman M, Kadirgama K. Experimental investigation and optimization of minimum quantity lubrication for machining of AA6061-T6. International Journal of Automotive \& Mechanical Engineering. 2015;11.

[5] Razak NH, Rahman MM, Kadirgama K. Cutting force and chip formation in end milling operation when machining nickelbased superalloy, Hastelloy C-2000. Journal of Mechanical Engineering and Sciences. 2017;14:2539-51.

[6] Najiha M, Rahman M, Kadirgama K. Performance of water-based $\mathrm{TiO}_{2}$ nanofluid during the minimum quantity lubrication machining of aluminium alloy, AA6061T6. Journal of Cleaner Production. 2016; In press.

[7] Izamshah R, Husna N, Hadzley M, Amran M, Shahir M, Amri M. Effects of cutter geometrical features on machining polyetheretherketones (PEEK) engineering plastic. Journal of Mechanical Engineering and Sciences. 2014;6:863-72. 
[8] Hamdan SH, Md Said AY, Biki JR. Surface finish when threading titanium-based alloy under dry machining. Journal of Mechanical Engineering and Sciences. 2014;7:1062-9.

[9] Abhang L, Hameedullah M. Power Prediction Model for Turning EN-31 Steel Using Response Surface Methodology. Journal of Engineering Science \& Technology Review. 2010;3.

[10] Hussain SA, Pandurangadu V, Kumar KP. Cutting power prediction model for turning of GFRP composites using response surface methodology. International Journal of Engineering, Science and Technology. 2011;3:161-71.

[11] Hanief M, Wani M. Artificial neural network and regression-based models for prediction of surface roughness during turning of red brass (C23000). Journal of Mechanical Engineering and Sciences. 2016;10:1835-45.

[12] Kadirgama K, Noor M, Rahman M. Optimization of surface roughness in end milling on mould aluminium alloys (AA6061-T6) using response surface method and radian basis function network. Jourdan Journal of Mechanical and Industrial Engineering. 2008;2(4):209-14.

[13] Antony J. Simultaneous optimisation of multiple quality characteristics in manufacturing processes using Taguchi's quality loss function. The International Journal of Advanced Manufacturing Technology. 2001;17:134-8.

[14] Dubey AK, Yadava V. Multi-objective optimization of Nd: YAG laser cutting of nickel-based superalloy sheet using orthogonal array with principal component analysis. Optics and Lasers in Engineering. 2008;46:124-32.

[15] Phadke MS. Quality engineering using robust design: Prentice Hall PTR; 1995.

[16] Yih-Fong T, Fu-Chen C. Multiobjective process optimisation for turning of tool steels. International Journal of Machining and Machinability of Materials. 2006;1:76-93.

[17] Lin C, Lin J, Ko T. Optimisation of the EDM process based on the orthogonal array with fuzzy logic and grey relational analysis method. The International Journal of Advanced Manufacturing Technology. 2002;19:271-7.

[18] Lo S-P. The application of an ANFIS and grey system method in turning toolfailure detection. The International Journal of Advanced Manufacturing Technology. 2002;19:564-72.

[19] Ho C-Y, Lin Z-C. Analysis and application of grey relation and ANOVA in chemical-mechanical polishing process parameters. The International Journal of Advanced Manufacturing Technology. 2003;21:10-4.

[20] Kadirgama K, Abou-El-Hossein K, Noor M, Sharma K, Mohammad B. Tool life and wear mechanism when machining Hastelloy C-22HS. Wear. 2011;270:25868.

[21] Kopac J, Krajnik P. Robust design of flank milling parameters based on greyTaguchi method. Journal of Materials Processing Technology. 2007;191:400-3.

[22] Arumugam PU, Malshe AP, Batzer SA. Dry machining of aluminum-silicon alloy using polished CVD diamond-coated cutting tools inserts. Surface and Coatings Technology. 2006;200:3399-403.

[23] Tosun N. Determination of optimum parameters for multi-performance characteristics in drilling by using grey relational analysis. The International Journal of Advanced Manufacturing Technology. 2006;28:450-5.

[24] Lin C. Use of the Taguchi method and grey relational analysis to optimize turning operations with multiple performance characteristics. Materials and Manufacturing Processes. 2004;19:209-20. 
[25] Al-Refaie A, Al-Durgham L, Bata N. Optimal parameter design by regression technique and grey relational analysis. Proceedings of the World Congress on Engineering; 2010.

[26] Saha A, Majumder H. Multi criteria selection of optimal machining parameter in turning operation using comprehensive grey complex proportional assessment method for ASTM A36. International Journal of Engineering Research in Africa: Trans Tech Publ; 2016. p. 24-32.

[27] Saha A, Mandal N. Optimization of machining parameters of turning operations based on multi performance criteria. International Journal of Industrial Engineering Computations. 2013;4:51-60.

[28] Majumder H, Saha A. Application of MCDM based hybrid optimization tool during turning of ASTM A588. Decision Science Letters. 2018;7:143-56.

[29] Rao RV. Advanced modeling and optimization of manufacturing processes: international research and development: Springer Science \& Business Media; 2010.

[30] Kadirgama K, Noor M, Rahman M. Optimization of surface roughness in end milling using potential support vector machine. Arabian Journal for Science and Engineering. 2012:1-7.

[31] Saha A, Majumder H. Performance analysis and optimization in turning of ASTM A36 through process capability index. Journal of King Saud UniversityEngineering Sciences. 2016.

[32] RamakoteswaraRao V, Ramanaiah N, Srinivasa Rao M, Sarcar MMM, Kartheek G. Optimisation of process parameters for minimum volumetric wear rate on AA7075-TiC metal matrix composite. International Journal of Automotive and Mechanical Engineering. 2016;13:3669-80. 